\title{
PRENATAL INTERVENTION FOR URINARY OBSTRUCTION AND MYELOMENINGOCELE
}

\author{
HUBERT S. SWANA, RONALD S. SUTHERLAND, LAURENCE BASKIN \\ Department of Urology, University of California San Francisco, and Department of Surgery, Tripler Army \\ Medical Center, San Francisco, California, USA
}

\begin{abstract}
Widespread use of ultrasonography has resulted in an increase in the recognition of fetal hydronephrosis. The enthusiasm that accompanied early interventions has been tempered by the experience and results obtained over the past 2 decades. The goal has remained the same: to identify patients with serious prenatal obstruction and to identify those which may benefit from intervention. Myelomeningocele remains a devastating congenital anomaly. Fetal and experimental studies suggested that patients with myelomeningocele could benefit from prenatal intervention. Advances in technology and perinatal management have made intervention for more complex malformations such as myelomeningocele possible. This article will review current knowledge and will detail rational management for the management of prenatal hydronephrosis. The current state of antenatal myelomeningocele repair and the urologic implications will be described as well.
\end{abstract}

Key words: fetus; congenital abnormalities; prenatal diagnosis; myelomeningocele; intrauterine; surgery; fetoscopy

Int Braz J Urol. 2004; 30: 40-8

\section{INTRODUCTION}

During the past 2 decades pediatric urologists have begun acquiring patients with antenatally detected conditions. With the widespread use of maternal ultrasound, fetal hydronephrosis has become increasingly detected, and it comprises the most common prenatally diagnosed malformation. The concept of the unborn child as a potential surgical patient has become firmly established (1). Fetal medicine has rapidly evolved since early experiences with the management of fetal hydronephrosis. With time, the natural history and pathophysiology of urinary tract obstruction has become better understood. Improvements in diagnostic imaging tools, advances in fetal urine sampling, enhanced interventional techniques and equipment, and a better understanding of the risks and outcomes in these babies have helped to develop rational intervention and observation strategies. Nev- ertheless, the management of the fetus with hydronephrosis has remained controversial.

The purpose of this article is to review antenatal intervention and its history. The basics of normal fetal development will be integrated with the techniques used to diagnose disorders of the urinary tract. Particular attention will be devoted to the diagnostic techniques of ultrasound, fetal urine sampling and amniocentesis. Newer modalities such as fetal magnetic resonance imaging (MRI) will be described. Intervention for patients with myelomeningocele and the implications for urinary tract function will be discussed. Methods of intervention will be described along with their indications, contraindications, and complications.

\section{SPECTRUM OF ANTENATAL DISORDERS: EMBRYOLOGY AND PATHOPHYSIOLOGY}

Perturbation of the developing ureteral bud and its intended target, the metanephric blastema by 
distal obstruction affects normal renal development (2-7). By the 5th week of gestation, the ureteral bud rises from the mesonephric duct. It then begins to lengthen and canalize. Induction of the metanephric blastema occurs by the end of week 7 . Primitive renal function begins between week 7 and 9 , and by week 20 , about $1 / 3$ of the total number of nephrons are present. Nephrogenesis is complete by the $32 \mathrm{nd}$ week of fetal life, after which no demonstrable increase in the number of glomeruli is noted (8-10).

The spectrum of deleterious changes seen in antenatal urinary obstruction is the result of multiple factors. They include the time of onset, duration, and degree of urinary obstruction. In general the earlier the obstruction occurs the more disturbed the development of the fetal kidney (8). Renal dysplasia, the most severe form of renal injury and maldevelopment, has been attributed to a very early effect of elevated pressures in the urinary (2) and alternatively by ureteral bud malposition with subsequent misconnection between the bud and the metanephric blastema $(4,11)$. Without ureteral bud induction, the blastema fails to develop. One sees clusters of disorganized metanephric structures surrounded by abundant fibrous tissue. Ninety per cent of cases of renal dysplasia are associated with urinary obstruction during nephrogenesis. Sonography is highly specific for diagnosing dysplasia and the demonstration of renal cysts in a fetus with known obstructive uropathy effectively indicates the presence of dysplasia (12). The absence of cortical cysts, however, does not exclude renal dysplasia.

Dilation of the urinary tract can be due to, ureteropelvic junction obstruction (UPJO), congenital obstructed and nonobstructed megaureter, multicystic kidney, duplication anomalies with upper pole ectopia or obstructing ureterocele, and vesicoureteral reflux (VUR) (13). Obstruction of the upper urinary tract from physiologic ureterectasis or from UPJO is rarely complete. One must also exclude physiological hydronephrosis which usually spontaneously resolves prior to delivery or within the first year of life (14) (Table-1).

More distal causes of obstruction include posterior urethral valves, urethral atresia, cloacal anomalies, and prolapsing, obstructing ureteroceles.
These entities can result in marked distortion of both ureters and kidneys as well as pathological bladder changes. The prune belly syndrome is rarely been associated with renal obstruction even though the urinary tract is massively dilated. Some have argued that the characteristic urinary tract dilation is a consequence of transient fetal urethral obstruction (15).

Spinal cord and subsequent vertebral formation begins at day 18 of gestation. Neural tube infolding (neurulation) occurs between 18 and 27 days of gestation and is normally followed by migration of mesodermal tissue around the developing spinal cord. The mesoderm gives rise to the vertebral arches, as well as the spinal and back musculature. The location, timing and extent of the abnormal closure lead to the varying degrees and levels of neural tube defects. Lesions can vary to include spina bifida occulta, (a closed tube defect), meningocele, (a protruding meningeal sac without neural elements), myelomeningocele (a menigeal sac with neural elements) and lipomeningocele (a meningeal sac with neural elements and fatty tissue). Myelomeningocele is the most common neural tube defect. Lumbar vertebrae are most commonly involved followed by sacral, thoracic and cervical vertebrae in decreasing frequency. Failure to close at the caudal end results in a distal defect with resultant lower limb paralysis and bladder dysfunction (16). An Arnold-Chiari type II malformation occurs in up to $85 \%$ of children with myelomeningocele (MMC). There can be herniation of the cerebellar tonsils through the foramen magnum. This can result in obstruction of the fourth ventricle and necessitates ventriculoperitoneal shunting.

Table 1 - Causes of prenatal hydronephrosis

Ureteropelvic Junction Obstruction
Multicystic Dysplastic Kidney
Megaureter
Vesicoureteral Reflux
Ureteral Ectopia
Ureterocele Ectopic
Prune Belly Syndrome
Posterior Urethral Valves
Urethral Atresia
Pelvic Tumor
Cloacal Anomaly

Ureteropelvic Junction Obstruction

Multicystic Dysplastic Kidney

Megaureter

Prune Belly Syndrom

Posterior Urethral Valves

Pelvic Tumor

Cloacal Anomaly 
Table 2 - Ultrasound grading scale of hydronephrosis

\begin{tabular}{llc}
\hline Grade & Central Renal Complex & Renal Parenchymal Thickness \\
\hline 0 & Intact & Normal \\
1 & Slight splitting & Normal \\
2 & Evident splitting confined within renal border & Normal \\
3 & Wide plitting pelvis outside renal border. Calices uniformly dilated & Normal \\
4 & Further dilation of renal pelvis and calices & Thin \\
\hline
\end{tabular}

From: Maizels M, Mitchell B, Kass E, Fernbach SK, Conway JJ.: Outcome of nonspecific hydronephrosis in the infant: a report from the registry of the Society of Fetal Urology. J Urol. 1994; 152: 2324-7.

Urology morbidity in patients with MMC is significant. Myelodysplasia can result in a poorly compliant bladder, sphincteric dysfunction, secondary vesicoureteral reflux, a predisposition to urinary tract infections, possible renal scarring and renal failure (17). Urologic morbidity is the sequela of neurologic injury. The neurologic deficit seen in MMC is believed to be due to several factors. The first is defective development. Evidence supporting a secondary insult to the exposed spinal cord has resulted in a "two hit hypothesis". Histologic findings support the idea that the exposed spinal cord is vulnerable to damage by physical trauma as the cord contacts the uterine wall. Physical trauma, and the toxic effects of amniotic fluid and meconium to the exposed spinal cord have been reported (18-20). Fetal lower limb movements have been described in fetuses with MMC at 16-17 weeks (21). Animal studies, in which laminectomy was performed at mid-gestation, compared in-utero repair to no treatment. The animals that underwent fetal intervention were spared flaccid paralysis and incontinence of urine and stool (22). Histologic specimens of bladder tissue from children with spina bifida reveal increased intracellular matrix between muscle bundles, decrease muscarinic receptor density abnormal smooth muscle growth, and decreased innervation (23-25). These factors likely contribute to bladder dysfunction in human spina bifida patients.

\section{DIAGNOSIS OF OBSTRUCTION}

\section{Ultrasound}

The evolution of fetal intervention has paralleled the advancements in ultrasound technology.
High resolution, real time imaging and the ability to choose focal zone depth have been major advances in ultrasonography (26). Fetal positioning plays a critical role in the interpretation and understanding of the fetal anatomy. The prone fetus is in the optimal position for imaging the kidneys (1). While the kidneys can be seen as early as the 15th week reliable imaging is not possible until week 18 (26).

Hydronephrosis is the most common cause of an abdominal mass in the neonate, and antenatal sonography readily detects fetal urinary tract dilation (1). Pelviectasis is found in $18 \%$ of normal fetuses (27). Both caliectasis and an anteroposterior pelvic diameter of greater than $10 \mathrm{~mm}$ have been proven to be reliable predictor of fetuses in need of postnatal urologic evaluation $(28,29)$. The Society of Fetal Urology has adopted a grading system form hydronephrosis, which is widely used by pediatric urologists today (Table-2).

Prenatal sonography is very sensitive in differentiating ureteropelvic junction obstruction from other causes of obstruction and dilation $(30,31)$.

While ultrasonography remains the primary imaging modality for the screening and evaluation of congenital abnormalities, it is not without limitations. Maternal obesity, oligohydramnios and suboptimal fetal position can make accurate imaging difficult. Early use of MRI was limited by slow acquisition times and was hampered by fetal motion. Newer methods have been developed that can reduce acquisition times and provide excellent image quality without the need for fetal sedation or paralysis (32). MRI can provide images unaffected by fetal position, maternal obesity, oligohydramnics, or overlying bowel and 
possibly could provide a definitive diagnosis of obstructive uropathy $(33,34)$.

MRI seems to be superior in identifying the intracranial lesions such as agenesis of the corpus callosum, cerebellar dysplasia and holoprosencephaly that can accompany myelomeningocele (35). In the future, clinical decisions may be based on analysis of chemical and molecular events with MRI (36). Presently, MRI is a useful adjunct to ultrasonography. MRI provides additional information in myelomeningocele, other complex fetal cases, and cases of hydronephrosis with indeterminate US studies.

\section{Fetal Urine and Amniotic Fluid Testing}

Invasive acquisition of fetal urine for analysis has become one of the most important measures of assessing fetal renal function. Measurement of fetal urine electrolytes and urinary proteins is a useful guide to the clinician in deciding whether prenatal intervention is indicated. Additional methods of assessing the overall status of the fetus include amniocentesis, chorionic villus sampling, percutaneous umbilical blood sampling (all for karyotyping), as well as amniotic fluid volume and its biochemical constituent measurement.

Fetal urine is normally hypotonic reflecting developing glomerular and tubular function (37). The amniotic fluid, in comparison, is somewhat hypertonic, and is not as reliable an index of renal function as the fetal urine. Determination of human fetal renal function is limited to simple concentration of specific urinary constituents. More physiologic measurements of glomerular function, while possible, are not routinely performed (38). Clearance of iothalamate has been done and shown to be nonpredictive of renal outcome (10). Retrospective analysis of individual urine constituents have shown that a sodium of less than $100 \mathrm{mEq} / \mathrm{L}$, osmolality less than $210 \mathrm{mOsm} / \mathrm{L}$ and chloride less than 90 $\mathrm{mEq} / \mathrm{L}$, if accompanied by lack of ultrasonographic evidence of dysplasia, are helpful in predicting residual fetal renal function. By categorizing patients according prognosis, assessment of the potential efficacy of intervention ca be made (39). Elder et al. (39) and Johnson et al. (40) separately suggested that single determinations of urinary electrolytes may not be useful. Johnson et al. (41) proposed providing transient relief of obstruction by vesicocentesis followed by sequential sampling ( 3 or 4 samples over several days) of urinary electrolytes. This was felt to provide an assessment of the severity of the renal injury and potential for reversibility of renal injury. Those fetuses that experience an improvement in their biochemical parameters following decompression may benefit most from interventional therapy (41). Others have suggested that sampling of fetal urine electrolytes and osmolarity is not an optimal method to evaluate fetal renal function and recommend continued search for a better substance (42-44). A serum marker, which has provided some clinical utility, is beta- 2 microglobilin. It is excreted by the kidney without placental cross-over so that fetal levels represent fetal renal function. One can see an elevation in renal dysplasia (45). Other urinary constituents commonly associated with the presence of renal disease include proteins such as albumin, retinol binding protein, and $\mathrm{N}$-acetyl-b-glucosaminidase have been studied (45). Unfortunately human fetal urine sampling lacks known control normals at different stages of development. Further limitation includes the inability to accurately and physiologically measure renal function by fractional excretion of biochemical constituents and glomerular filtration without risky invasive fetal and maternal testing (46).

\section{INTERVENTIONAL TECHNIQUE}

\section{Current Indications and Contraindications}

For most fetuses with obstructive uropathy, intervention is not necessary (47) (Figure-1). The selection criteria for fetal therapy of obstruction evolved such that patient selection is presently good enough to avoid intervention in patients who are either too well (no benefit) or too ill to recover (48). It has been conclusively shown that decompression in utero will restore amniotic fluid, which can prevent the development of fatal pulmonary hypoplasia. What seems less clear is whether or not in utero decompression can arrest or reverse cystic dysplastic changes caused by obstruction (48).

Spontaneous resolution of hydronephrosis is common, which has led to a more cautious approach 


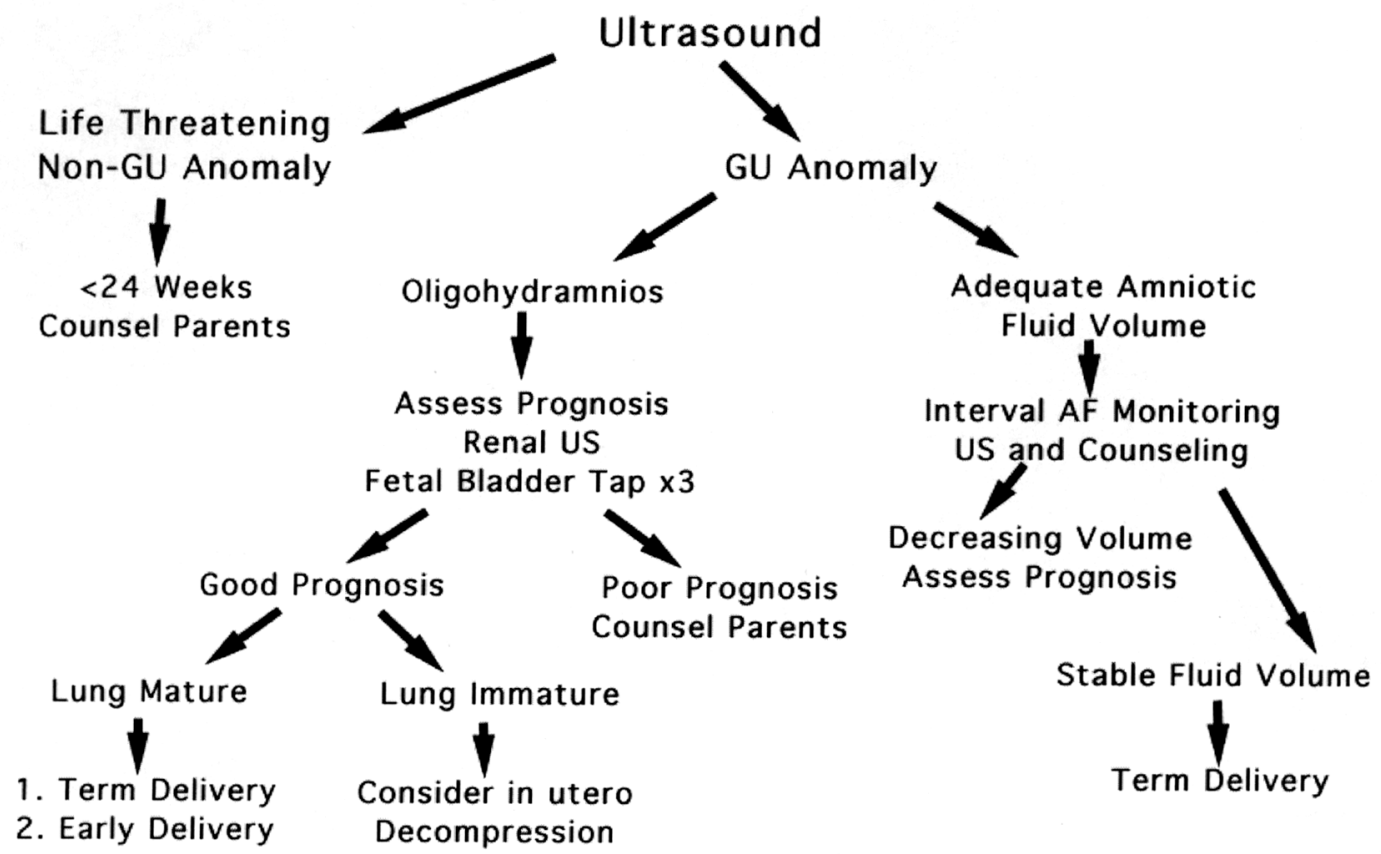

Figure 1 - The fetus with bilateral hydronephrosis. Treatment algorithm. (Courtesy of Doctor Nalin Gupta, Department of Neurosurgery, University of California San Francisco, California USA)

to fetal intervention $(1,49)$. In most cases with normal amniotic fluid volume, the mother should be followed by serial ultrasound examinations, and the fetus should be evaluated and treated postnatally. If moderate to severe oligohydramnios develops, the fetus should undergo complete prognostic evaluation to assess the potential for normal renal and pulmonary function at birth. If the ultrasound demonstrates presence of dysplasia, aggressive obstetrical care or prenatal decompression is not indicated. When preserved renal function is predicted, early delivery for postnatal decompression is indicated if the lungs are mature. Early delivery usually does not compromise pulmonary function as long as amniotic fluid volume has been maintained (1). If the lungs are immature, however, in-utero decompression can be considered.

\section{METHODS OF INTERVENTION}

\section{Urinary Tract}

Early attempts at bladder decompression in the late 70 's and early 80 's attempted a Seldinger- type procedure, but with limited success. A tight fitting double pigtail catheter placed over a puncture needle using a pusher worked; although it was far from ideal. Due to the difficulties in catheter placement, migration and plugging, Malecot-type and external coil type catheters were developed.

Open fetal surgery began in the early 1980's, and was performed on eight highly selected cases of obstructive uropathy from 18-24 weeks gestation. Unfortunately this method of treatment carried significant morbidity predominantly from preterm labor $(47,48,50)$. As a result, open fetal surgery to correct urinary tract obstruction has not since been performed. In those early patients, open decompression procedures included cutaneous vesicostomy in 7 and bilateral ureterostomies in 1. Only 4 had prolonged return of normal amniotic fluid and had adequate pulmonary function at birth. Of these only two have normal renal function at ages 5 and 8 years (51).

With advances in endoscopic equipment, the technique of transuterine endoscopy was developed at the University of California, San Francisco (52). 
MacMahon and associates reported a similar fetoscopic approach in a human fetus with prune belly syndrome and oligohydramnios at $17+$ weeks. They used a Neodymium-Yag laser to create a vesicoamniotic shunt, which was successful at restoration of the amniotic fluid volume. The fistula closed by 33 weeks and the child was delivered early with normally developed lungs (53). Fetal cystocopy and valve ablation has been reported. Both antegrade and retrograde techniques have been reported. Flexible and rigid instruments were used as well. Significant fetal mortality was reported (54).

\section{Myelomeningocele}

Repair of MMC has been attempted both endoscopically and through open surgery via a hysterotomy. While technically possible, surgery for MMC is not presently being performed via a fetoscopic approach. Fetoscopy is limited by the need for multiple port sites, which can lead to membrane fixation and rupture as the uterus enlarges. In addition it is difficulty to visualize large spinal defects and requires prolonged operative times (55).

Open fetal surgery requires careful planning (Figure-2). Attempts at enhancing fetal lung maturity are made through the use of preoperative glucocoritosteroid administration to the mother. Broad spectrum antibiotics and balanced anesthesia allow the procedure to take place. The amniotic fluid is removed and kept in sterile warm syringes. A standard neurosurgical closure is performed through an approximately $8 \mathrm{~cm}$ hysterotomy. The neural placode is dissected from the adjacent arachnoid tissue and placed in the spinal canal. The dura is then dissected off for another layer of coverage. The skin then is freed for a final layer of closure. The amniotic fluid and added antibiotics are replaced and the uterus closed. Phophylactic tocolytics are then used (56).

\section{Results and Complications}

\section{Urinary Tract}

Early results of prenatal bladder shunting reassured physicians that the procedures could be performed safely and that catheter drainage was well tolerated in most cases. Whether prenatal shunting improves outcome remains a different matter. Patient
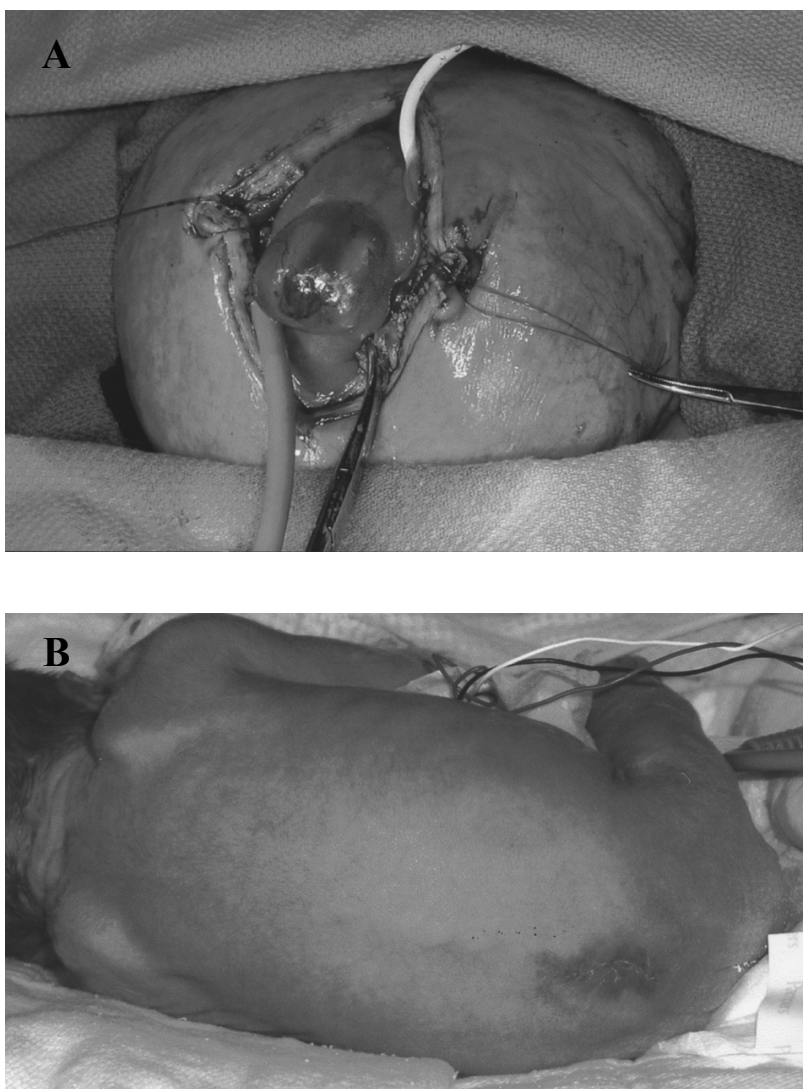

Figure 2 - Fetal surgery for myelomeningocele. Pre-operative (A) and post-operative (B) images. (Courtesy of Doctor Nalin Gupta, Department of Neurosurgery, University of California San Francisco, California USA).

selection is critical. One must find a dilated urinary tract with severe enough obstruction to compromise renal and pulmonary function at birth, and yet not so severe that renal function cannot be salvaged with decompression (1).

Reviews by Coplen, McLorie and Baskin have shown several things. First, obstruction and dysplasia are difficult to predict. Second, while technically feasible, fetal interventions were associated with only a $47 \%$ survival rate and a $45 \%$ of fetuses had complications $(39,56-58)$. Third, even though oligohydramnios could be reversed, the ability to sustain good renal function was variable. Lastly, specific prenatal parameters that were effective in predicting good renal function have note been found $(52,58)$.

The most common complication arising from open in utero fetal intervention is the instigation of 
preterm labor (50). Catheters can fail either by plugging. Incorrect placement despite ultrasound guidance has resulted in fetal injury, and death (59). Reinsertions increase the risks of fetal injury and infections. Chorioamnionitis can sometimes resulting in pregnancy termination (51).

\section{Myelomeningocele}

Prenatal surgery for myelomeningocele has yielded some unexpected outcomes. Tubbs et al. were not able to show improved lower extremity function in patients that underwent intrauterine intervention (59).

Bruner et al. compared 29 fetal surgery patients with 23 controls matched for level of defect, diagnosis, calendar time and practice parameters (60). They reported a statistically significant $(\mathrm{P}=0.01)$ decrease in the need for ventriculoperitonel shunt placement and a lower incidence of hindbrain herniation $(\mathrm{P}=0.001)$. Patients who underwent fetal surgery did however have a higher risk of oligohydramnios $(48 \%$ vs. $4 \% ; \mathrm{P}=0.001)$, and admissions for preterm contractions $(50 \%$ vs. $9 \% ; \mathrm{P}=0.002)$. They were also more susceptible to prematurity. Age at delivery was earlier (33 vs. 37 weeks; $\mathrm{P}<0.001$ ) and birth weight were lower (2171 vs. 3075 gm; $\mathrm{P}<0.001$ ) (56).

The effect of fetal intervention for myelomeningocele on postnatal bladder function has been studied $(57,58)$. Despite the early repair, patterns of abnormal bladder function were exhibited. One still sees poor compliance, poor detrusor contractility, detrusor-sphincter dysynergia, hydronephrosis and vesicoureteral reflux. The previously described global defect in bladder development makes success of fetal surgery to preserve or improve bladder function unlikely. Additional studies are ongoing.

\section{CONCLUSIONS}

The field of fetal medicine has grown over the past two decades. Well-defined animal studies have yielded clues to the natural history and pathogenesis of obstructive uropathy and the efficacy of interventional techniques to ameliorate the sequelae of such obstruction. With advances in technology, the complexity of anomalies, which can be treated, has increased, as evidenced by the growing experience with fetal myelomeningocele repair. In addition these new scenarios provide new ethical challenges. Carrying out procedures in human fetuses must continue to be appropriately cautious and circumspect. The uncertainties and true pathologic processes surrounding urinary tract obstruction must continue to be explored. More reliable methods of determining fetal renal function lay on the horizon. Interventional techniques continue to evolve and improve. Because of the potential risks for preterm labor and maternal compromise, fetal surgery should continue to be performed only for carefully selected cases at centers that are equipped with a multidisciplinary health care team committed to ongoing, well-designed research protocols.

\section{REFERENCES}

1. Harrison M, Filly R: The Unborn Patient, 2nd ed. Philadelphia, W.B. Saunders Co. 1991.

2. Beck AD: The effect of intra-uterine urinary obstruction upon the development of the fetal kidney. J Urol. 1971; 105: 784-9.

3. Berman DJ, Maizels M: The role of urinary obstruction in the genesis of renal dysplasia. J Urol. 1983; 128: 1091-6.

4. Barrett DM, Wineland RE: Renal cell carcinoma in multicystic dysplastic kidney. Urology. 1980; 15: 1524.

5. Longino LA, Martin LW: Abdominal masses in the newborn infant. Pediatrics. 1958; 21: 596-604.

6. Glick PL, Harrison MR, Noall RA, Villa RL: Correction of congenial hydronephrosis in utero III. Early mid-trimester ureteral obstruction produces renal dysplasia. J Pediatr Surg. 1983; 18: 681-7.

7. Bellinger MF, Comstock CH, Grosso D, Zaino R: Fetal posterior urethral valves and renal dysplasia at 15 weeks gestational age. J Urol. 1983; 129: 1238-9.

8. Gasser B, Mauss Y, Ghnassia JP, Favre R, Kohler M, $\mathrm{Yu} \mathrm{O}$, et al.: A quantitative study of normal nephrogenesis in the human fetus: its implication in the natural history of kidney changes due to low obstructive uropathies. Fetal Diagn Ther. 1993; 8: 37184.

9. Potter E: Normal and Abnormal Development of the Kidney. Yearbook Medical. 1972.

10. Glick PL, Harrison MR, Golbus MS, Adzick NS, Filly 
RA, Callen PW: Management of the fetus with congenital hydronephrosis II: Prognostic criteria selection for treatment. J Pediatr Surg. 1985; 20: 376-87.

11. King LR: The Management of Multicystic Kidney and Ureteropelvic Junction Obstruction. In King L (ed.), Urologic Surgery in Neonates and Young Infants. Philadelphia, W.B. Saunders Co. 1988; p. 140.

12. Mahony HS, Filly RA, Callen PW, Hricak H, Gobbus MS, Harrison MR, et al.: Fetal renal dysplasia: sonographic evaluation. Radiology. 1984; 152: 143-6.

13. Gordon AC, Thomas DFM, Arthur RJ, Irwing HC, Smith SE: Prenatally diagnosed reflux: a follow-up study. Br J Urol. 1990; 65: 407-12.

14. Anderson PAM, Rickwood AMK: Featurers of primary vesicoureteric reflux detected by prenatal sonography. Br J Urol. 1991; 67: 267.

15. Snow BW, Duckett JW: Prune Belly Syndrome. In: Gillenwater JY, Grayhack JT, Howards S, Duckett JW (eds.), Adult and Pediatric Urology, St Louis, Mosby. 1991; 2nd ed., p. 1921.

16. Moore KL, Persaud TVN: The Developing Human: Clinically Oriented Embryology. Philadelphia, W.B. Saunders Co. 2003; pp. 428-33.

17. Muller T, Arbeiter K, Aufricht C: Renal function in myelomeningocele: risck factors, chronic renal failure, renal replacement therapy and transplantation. Curr Opin Urol. 2002; 12: 479-84.

18. Meuli M, Meuli-Simmeti C, Hutchins GM, Seller MJ, Harrison MR, Adzick NS: The spinal cord lesion in human fetuses with myelomeningocele: Implications for feta surgery. J Ped Surg. 1997; 32: 448-52.

19. Drewek MJ, Bruner JP, Whetsell WO, Tulipan N: Quantitative analysis of the toxicity of human amniotic fluid to cultured rat spinal cord. Ped Neurosurg. 1997; 27: 190-3.

20. Correia-Pinto J, Reis JL, Hutchins GM, Baptista MJ, Estevão-Costa J, Flake AW, et al.: In utero meconium exposure increases spinal cord necrosis in a rat model of myelomeningocele. J Ped Surg. 2002; 37: 488-92.

21. Korenromp MJ, van Good JD, Bruinese HW, Kriek R: Early fetal movements in myelomeningocele. Lancet. 1986; 8: 917-8.

22. Meuli M, Meuli-Simmen, Hutchins GM, Yingling CD, Hoffman KM, Harrison MR, et al.: In utero surgery rescues neurologic function at birth in sheep with spina bifida. Nat Med. 1995; 1: 342-7.

23. Shapiro E, Becich MJ, Perlman E, Lepor H: Bladder wall abnormalities in myelodysplastic children: a computer assisted morphometric analysis. J Urol. 1991; 145: 1024-9.
24. Gup DI, Baumann M, Lepor H, Shapiro E: Muscarinic cholinergic receptors in normal pediatric and myelodysplastic bladders. J Urol. 1989; 142: 595-9.

25. Shapiro E, Seller MF, Lepor H, Kalousek DK, Hutchins GM, Perlman EJ, et al.: Altered smooth muscle development in the lower genitourinary and gastrointestinal tract of the male fetus with myelomeningocele. J Urol. 1998; 160: 1047-53.

26. Merguuerian P: The evaluation of prenatally detected hydronephrosis. Mongraph Urol. 1995; 16: 1-5.

27. Hoddick WK, Filly RA, Mahony BS, Callen PW: Minimal fetal renal pyelectasis. J Ultrasound Med. 1985; 4: 85-9.

28. Cendron M, Morin L, Crombleholme T: Early minimal fetal hydronephrosis: clinical outcomes and implications for management. American Academy of Pediatrics. Pediatric Urology Sections (Dallas, Texas). 1994; Abstract \# 30.

29. Birken G, Vane D, King Dea: Adenocarcinoma arising in a multicystic dysplastic kidney. Pediatr Surg. 1985; 20: 619 .

30. Manning FA, Harrison MR, Rodeck C: Catheter shunts for fetal hydronephrosis and hydrocephalus. N Engl J Med. 1986; 315: 336-40.

31. Yamashita Y, Namimoto T, Abe Y, Takahashi M, Iwamasa J, Mujazaki K, et al.: MR imaging of the fetus by a HASTE séquense. AJR. 1997; 168: 513-9.

32. Coakley FV, Hriak H, Filly RA, Barkovich AJ, Harrison MR: Complex fetal disorders: effect of MR imaging on management-preliminary clinical experience. Radiology. 1999; 213: 691-6.

33. Aaronson OS, Hernanz-Schulman M, Bruner JP, Reed GW, Tulipan NB: Myelomeningocele: Preneatal evaluation - Comparison between transabdominal US and MR imaging. Radiology. 2003; 227: 839-43.

34. Levine D, Barnes PD, Madsen JR, Abbott J, Mehta T, Edelman RR: Central nervous system abnormalities assessed with prenatal magnetic resonance imaging. Obstet Gynecol. 1999; 94: 1011-9.

35. Tempany CMC, McNeil BJ: Advances in biomedical imaging. JAMA. 2001; 285: 562-7.

36. Woodard Jr: Neonatal and perinatal emergencies. In: Harrison JH, Gittes RF, Perlmutter AD, et al. (eds.): Campbell's Urology, Philadelphia, W.B. Saunders Co. 1979, 4th ed., p. 1855.

37. Adzick NS, Sutton LN, Crombelhome TM, Flake AW: Successful fetal surgery for spina bifida. Lancet. 1998; 852: 1675-6.

38. Crombleholme TM, Harrison MR, Golbus MS, Longaker MT, Langer JC, Callen PW, et al.: Fetal in- 
tervention in obstructive uropathy: prognostic indicators and efficacy of intervention. Am J Obstet Gynecol. 1990;162:1239-44

39. Elder JS, O'Grady JP, Ashmead G, Duckett JW, Philipson E: Evaluation of fetal renal function: unreliability of fetal urinary electrolytes. J Urol. 1990; 144: $574-8$

40. Johnson MP, Corsi P, Bradfield W, Hume RJ, Smith C, Flake AW, et al.: Sequential analysis improves evaluation of fetal renal function in obstructive uropathy. Am J Obstet Gynecol. 1995; 173: 59-65.

41. Johnson MP, Bukowski TP, Reitleman C, Isada NB, Pryde PG, Evans ML: In utero surgical treatment of fetal obstructive uropathy: a new comprehensive approach to identify appropriate candidates for vesicoamniotic shunt therapy. Am J Obstet Gynecol. 1994; 170: 1770-6.

42. Elder JS, Duckett JW, Snyder HM: Intervention for fetal obstructive uropathy: has it been effective? The Lancet. 1987; Oct 31, 8566: 1007-10.

43. Wilkins IA, Chitkara U, Lynch L, Goldberg JD, Mehalek KE, Berkowitz RL: The nonpredictive value of fetal urinary electrolytes: Preliminary report of outcomes and correlations with pathologic diagnosis. Am J Obstet Gynecol. 1987; 157: 694-8.

44. Mandell J, Blyth BR, Peters CA, Retik AB, Estroff JA, Benacerraf BR: Structural genitourinary defects detected in utero. Radiology. 1991; 178: 193-6.

45. Dommergues M, Muller F, Ngo S, Hohlfeld P, Oury JF, Bidat L, et al.: Fetal serum beta-2-microglobulin predicts postnatal renal function in bilateral uropathies. Kid Int. 2000; 58: 312-6.

46. Longaker MT, Golbus MD, Filly RA, Rosen MA, Chang SW, Harrison MR: Maternal outcome after open fetal surgery. JAMA. 1991; 265: 737-41.

47. Adzick NS, Harrison MR: The unborn surgical patient. Curr Probl Surg. 1994; 31: 1-68.

48. Onen A, Jayanthi VR, Koff SA: Long term follow-up of prenatally detected severe bilateral newborn hydronephrosis initially managed nonoperatively. J Urol. 2002; 168: 1118-20.

49. Harrison MR, Adzick NS: The fetus as a patient. Surgical considerations. Ann Surg. 1991; 213: 279-91.

50. Crombleholme TM, Harrison MR, Golbus MS, Longaker MT, Langer JC, Callen PW, et al.: Fetal intervention in obstructive uropathy: prognostic indicators and efficacy of intervention. Am J Obstet Gynecol. 1990; 162: 1239-44.

51. Estes JM, MacGillivray TE, Hedrick MH, Adzick NS, Harrison MR: Fetoscopic surgery for the treatment of congenital anomalies. J Pediatr Surg. 1993; 27: 950-4.

52. Najmaldin A, Burge DM, Atwell JD: Fetal vesicoureteric reflux. Br J Urol. 1990; 65: 403-6.

53. Quintero RA, Hume R, Smith C, Johnson MP, Cotton DB, Romero R, et al.: Percutaneous fetal cystoscopy and endoscopic fulgaration of posterior urethral valves. Am J Obstyet Gynecol. 1995: 172: 206-9.

54. Olutoye OO, Adzick NS: Fetal surgery for myelomeningocele. Semin Perinatol. 1999; 23: 462-73.

55. Coplen DE: Prenatal intervention for hydronephrosis. J Urol. 1997; 157: 2270-7.

56. McLorie G, Farhat W, Khoury A, Geary D, Ryan G: Outcome analysis of vesicoamniotic shunting in a comprehensive population. J Urol. 2001; 166: 1036-40.

57. Holmes N, Harrison MR, Baskin LS: Fetal surgery for posterior urethral valves: Long-term postnatal outcomes. Pediatrics. 2001; 108: E7.

58. Harrison MR, Golbus MS, Filly RA, Anderson RL, Flake AW, Rosen M, et al.: Feta hydronephrosis: selection and surgical repair. J Pediatr Surg. 1987; 22: 556-8.

59. Tubbs RS, Chambers MR, Smyth MD, Bartolucci AA, Bruner JP, Tulipan N, et al.: Late gestational myelomeningocele repair does not improve lower extremity function. Ped Neuro Surg. 2003; 38: 128-32.

60. Bruner JP, Tulipan N, Paschall RL, Boehm FH, Walsh WF, Silva SR, et al.: Fetal surgery for myelomeningocele and the incidence of shunt-dependent hydrocephalus. JAMA. 1999; 282: 1819-25.

Received: October 13, 2003 Accepted: November 17, 2003 